\title{
Children and mothers at clinics: who is disturbed?
}

\author{
D B CUNDALL
}

\author{
Department of Paediatrics and Child Health, St James's University Hospital, Leeds
}

\begin{abstract}
SUMMARY One hundred and eighty one white children aged 6 to 11 years who were attending medical outpatient clinics with their mothers were studied to assess the prevalence of psychological disturbance in the children, and anxiety and depression in the mothers. Teachers were also asked to assess the children independently using the Rutter scales. Mothers assessed 70 $(39 \%)$ of the children as being disturbed, 20 of whom were also assessed as being disturbed by their teachers. A further 15 children were assessed as being disturbed by their teachers but not by their mothers. Thirty five (19\%) of the mothers assessed themselves as anxious and two as depressed using the hospital anxiety and depression scale. Anxious and depressed mothers were significantly more likely to assess their child as being disturbed. In contrast, the teachers' assessments of the children were not affected by the mental state of the mothers. These findings confirm that mothers' perceptions of their children are modified by their own moods.
\end{abstract}

The availability of a wide range of facilities for diagnosis and treatment, and a healthy concern for the psychological wellbeing of children means that paediatrics is increasingly becoming an outpatient specialty. An assessment of the psychology of the child and the family is crucial to understanding the child and his or her illness. A detailed assessment of psychological function is hardly practicable, however, within the constraints of the usual outpatient consultation. Recent work with adults has shown that useful information may be obtained from brief questionnaires that assess anxiety and depression given to patients while they are waiting for outpatient consultations. ${ }^{1}$

This study was undertaken to determine the prevalence of psychiatric disturbance, which was assessed by their mothers and schoolteachers, in a sample of children attending outpatient clinics and the prevalence of anxiety and depression in the mothers, which they assessed themselves. The study also explored the correlation between the separate assessments of the children and their mothers' anxiety and depression with facts about the illness and the family.

Specific hypotheses were that maternal anxiety and depression affect mothers' perceptions of their children's disturbance, and that severity of the child's illness is more psychologically disturbing to the mother than to the child.

\section{Patients and methods}

One hundred and eighty one white children aged 6 to 11 years who were attending medical outpatient clinics accompanied by their mothers were studied. Many of the Asian mothers attending the clinics did not have a good command of English, and so only white children were included in the study. The clinics sampled were mainly general paediatric clinics, but also some subspecialty clinics for children with diabetes, cancer, cystic fibrosis, renal problems, and enuresis. None of the clinics specifically dealt with children with emotional or psychiatric problems, nor were children selected for study because of psychological problems; the length of time immediately prior to consultation was the main factor which determined their inclusion in the study. Towards the end of the study some children with asthma and enuresis were not included because these diagnoses were already well represented in the sample.

Children and their mothers were greeted in the waiting area and invited to take part in the study while awaiting their consultation. They were told that the study aimed to find out how mothers and children feel when they attend outpatient clinics, but not about how they felt about the clinic or hospital. If both mother and child agreed to participate they were given questionnaires to fill in 
individually. Two mothers refused to participate in the study.

The mother was first asked to complete a short questionnaire about her marital and employment status, the number of other children in the family, and the position of the child within the family. She then completed a Rutter $\mathrm{A}_{2}$ scale $^{2}$ about the child's health and behaviour, and finally completed a hospital anxiety and depression scale about herself, ${ }^{1}$ which was prefaced by a paragraph explaining why parents' feelings may be useful in understanding the child. Concurrently the child completed a children's version of the hospital anxiety and depression scale, comprising six questions. Children aged 8 to 11 then completed the depression self rating scale for children. ${ }^{3}$ Written consent was obtained for a Rutter $\mathrm{B}_{2}$ scale to be sent to the child's schoolteacher for completion. ${ }^{4}$

The author was present in the waiting area, usually seated next to the mother and child, and helped children to read their questions if necessary. Mothers and children took between 10 and 20 minutes to complete their questionnaires.

The Rutter $\mathrm{A}_{2}$ scale comprises 31 questions and statements on the child's health, habits, and behaviour over the preceding 12 months. The mother could give one of three responses to each question or statement: (a) does not apply; (b) applies somewhat; (c) certainly applies. Responses were scored 0,1 , or 2 , respectively. A score of 13 or more has been found to be the best discriminator between children who are psychiatrically disturbed and those who are not. ${ }^{2}$ The Rutter $B_{2}$ scale comprises 26 statements with three possible responses, which are scored like the Rutter $\mathrm{A}_{2}$ scale. A score of 9 or more has been shown to discriminate best between disturbed and non-disturbed children and this was used in this study.

The hospital anxiety and depression scale, which was validated with adults attending outpatient clinics in Leeds, includes 14 statements about how the person has felt in the past week, seven of which are designed to measure depression, and seven anxiety. ${ }^{1}$ There are four possible responses to each statement, which are scored from $0-3$. A score of 11 or more on the relevant subscale indicates definite anxiety or depression, and a score of 8 to 10 mild anxiety or depression.

The following information was extracted from the child's medical notes and coded for analysis: age, main diagnosis, type of drug treatment, period of time attending that clinic, number of clinic attendances, previous attendance at other clinics, and previous admission to hospital. Diagnoses were grouped into 'minor', 'major', or 'very serious' depending on whether they were chronic, their degree of severity, and the mortality risk. For example, asthmatics who required regular treatment with steroids or theophyllines were classified as 'major', and other asthmatics were classified as 'minor'. Diabetes mellitus, cystic fibrosis, epilepsy, and nephrotic syndrome were classified as 'major', and all children with cancer or renal failure were classified as having 'very serious' diseases. Classification of the severity of diagnosis was made without knowledge of the psychological ratings. The $\chi^{2}$ test was used for initial analysis. Correlations between variables were explored further using a stepwise logistic regression analysis (BMDP statistical package) to determine which variables seemed to predict mothers' ratings of the children's disturbance.

Permission for the study was granted by the ethical committee of Leeds Eastern Health Authority, and by the director of education for Leeds City Council.

\section{Results}

Ninety three $(51 \%)$ of the children studied were boys. There was an even distribution of children across age groups: $59(33 \%)$ were 6 to 7 years old, 59 $(33 \%)$ were 8 to 9 , and $63(35 \%) 10$ to 11 . Table 1 summarises the principal diagnoses of the children studied. Diagnoses were classified as minor in 109 $(60 \%)$, major in $54(30 \%)$, and very serious in 18 $(10 \%)$. Eighty seven $(48 \%)$ of the children were not taking any drugs, $43(24 \%)$ were taking sympathomimetic drugs for asthma, nine $(5 \%)$ oral steroids, six $(3 \%)$ insulin, six $(3 \%)$ anticonvulsants, and 30 $(17 \%)$ were having other forms of drug treatment.

Table 1 Diagnoses of 181 children studied

\begin{tabular}{|c|c|}
\hline Diagnosis & $\begin{array}{l}\text { No of } \\
\text { children }\end{array}$ \\
\hline Asthma & \multirow[t]{2}{*}{41} \\
\hline Urinary tract infections & \\
\hline Recurrent hacmaturia & \multirow[t]{2}{*}{33} \\
\hline Nephrotic syndrome & \\
\hline Enuresis & \multirow[t]{3}{*}{18} \\
\hline Soiling $\}$ & \\
\hline Abdominal pains & \\
\hline Migraine & \multirow[t]{2}{*}{18} \\
\hline Headaches & \\
\hline $\begin{array}{l}\text { Joint pains } \\
\text { Malignancy }\end{array}$ & 15 \\
\hline Epilepsy & 8 \\
\hline Renal failure & 7 \\
\hline Diabetes mellitus & 6 \\
\hline Non-malignant hacmatological disorders & 6 \\
\hline Cystic fibrosis & 3 \\
\hline Short stature & 3 \\
\hline $\begin{array}{l}\text { Others. including. inflammatory } \\
\text { bowel discaise. congenital adrenal } \\
\text { hyperplasia, recurrent respiratory }\end{array}$ & 23 \\
\hline
\end{tabular}


Twenty three $(13 \%)$ of the children were attending the clinic for the first time. Of the remaining 158, 44 were attending clinic more than 10 times a year. Fifty eight $(32 \%)$ had attended other outpatient clinics, and $121(67 \%)$ had been admitted to hospital.

The mean number of children in each family was $2 \cdot 5$, and $75(41 \%)$ of those in the study were the first child in their family. Of the mothers, $148(82 \%)$ described themselves as married, $22(12 \%)$ as divorced, one as separated, and 10 as single. Forty $(23 \%)$ of the children came from families in which the head of the household was unemployed. Of the parents, $72(40 \%)$ were manually employed and 65 $(36 \%)$ had other types of jobs. One mother did not understand all the questions she was required to answer, and one mother refused permission for the Rutter $B_{2}$ scale to be sent to her child's schoolteacher. Seven $(4 \%)$ of the Rutter $B_{2}$ assessments were not returned by the schoolteachers.

Children's disturbance assessed by mothers and teachers. Seventy $(39 \%)$ of the children were assessed as being disturbed by their mothers, and of these, 20 were also identically assessed by their teachers. An additional 15 were assessed as being disturbed by their teachers but not by their mothers. Both mothers and teachers assessed proportionately more boys than girls as being disturbed. Forty $(44 \%)$ of the boys and $30(34 \%)$ of the girls were assessed as being disturbed by their mothers. Twenty two $(26 \%)$ of the boys and $13(15 \%)$ of the girls were assessed as being disturbed by their teachers.

Maternal anxiety and depression. Thirty four (19\%) of the mothers regarded themselves as definitely anxious and $47(26 \%)$ as mildly anxious. Two mothers felt that they were definitely depressed and
$14(8 \%)$ that they were mildly depressed. Eleven $(28 \%)$ and $14(36 \%)$ of mothers from homes where the head of the household was unemployed were definitely and mildly anxious, respectively, compared with $23(17 \%)$ and $33(24 \%)$ of mothers where the head of the household was employed $(p<0 \cdot 05)$.

Correlation with children's disturbance and maternal anxiety and depression. Table 2 summarises the variables that were significantly related to children's disturbance. These variables were likely to be interrelated, so a stepwise logistic regression analysis was done to discover which variables were most predictive of children's disturbance, as assessed by their mothers. Four (maternal anxiety, maternal depression, number of clinic attendances, and family size) were found to be independently associated with the mothers' assessments of their children's disturbance. Using stepwise logistic regression analysis, only maternal anxiety $(p=0.01)$ and family size $(p=0.04)$ were significant.

Children's disturbance and maternal anxiety or depression related to severity of child's illness. Nine $(50 \%)$ of the very seriously ill children, $20(37 \%)$ of the children with major illnesses, and $41(38 \%)$ of those with minor illnesses were considered to be disturbed by their mothers. None of the very seriously ill children, $14(29 \%)$ of the children with major illnesses, and $21(20 \%)$ of those with minor illnesses were thought to be disturbed by their teachers. Twenty eight $(24 \%)$ of the children who had been previously admitted to hospital were assessed as being disturbed by their teachers, compared with seven $(12 \%)$ of the children who had not been admitted $(\mathrm{p}<0.05)$.

Six $(33 \%)$ of the mothers of children with very serious illnesses were definitely anxious, compared with $10(19 \%)$ of the mothers of children with major

Table 2 Variables related to mothers' and teachers' assessments of children

\begin{tabular}{|c|c|c|c|c|c|c|}
\hline & \multicolumn{3}{|c|}{$\begin{array}{l}\text { Mothers' assessments of children } \\
\text { (Rutter } A_{2} \text { scale) }\end{array}$} & \multicolumn{3}{|c|}{$\begin{array}{l}\text { Teachers' assessments of children } \\
\text { (Rutter } B_{2} \text { scale) }\end{array}$} \\
\hline & Disturbed & Not disturbed & $p$ value & Disturbed & Not disturbed & $p$ value \\
\hline \multicolumn{7}{|l|}{ Maternal anxicty: } \\
\hline Definitely anxious & 20 & 14 & \multirow{3}{*}{$<0 \cdot(01$} & 6 & 28 & \multirow{3}{*}{ NS } \\
\hline Mildly anxious & 22 & 24 & & 8 & 35 & \\
\hline Not anxious & 28 & 70 & & 19 & 75 & \\
\hline \multicolumn{7}{|l|}{ Maternal depression: } \\
\hline Definitely and mildly depressed & 10 & $\left.\begin{array}{r}6 \\
13\end{array}\right\}$ & \multirow[t]{2}{*}{$<0 \cdot 05$} & 3 & $11\}$ & NS \\
\hline \multicolumn{6}{|l|}{ Family size: } & \\
\hline Four or more children in family & 4 & $18\}$ & \multirow[t]{2}{*}{$<0.05$} & 8 & 14 & \multirow[t]{2}{*}{$<0 \cdot 05$} \\
\hline Three or fewer children in family & 65 & $92\}$ & & 27 & 123 & \\
\hline \multicolumn{7}{|l|}{ Employment of head of household: } \\
\hline Unemployed & 19 & 21 & \multirow{2}{*}{ NS } & 14 & 24 & \multirow{2}{*}{$<0 \cdot 01$} \\
\hline Employed & 50 & $87\}$ & & 19 & 112 & \\
\hline
\end{tabular}


illnesses, and $18(17 \%)$ of those with minor illnesses. Maternal depression was not related to the severity of the child's illness; one child with a very serious illness had a definitely depressed mother, the other definitely depressed mother having a child with a minor illness.

Other variables, like type of illness, drug treatment, and number of clinic attendances were not significantly related to the children's or mothers' disturbances.

\section{Discussion}

The amount of information obtained about a patient's psychological state is necessarily limited by the time available for assessment in the outpatient clinic. It is therefore important to select appropriate methods to facilitate this. The Rutter scales are widely used, having been well validated in a community study on the Isle of Wight: they detect psychiatric disturbance in children, and are more reliable for detecting disorders of conduct than affective disorders.

The prevalence of disturbance in children found in this study was similar to that found by Fitzgerald in children attending outpatient clinics in London. ${ }^{5}$ Using the teachers' questionnaire, the rates of disturbance found in Leeds $(26 \%$ among boys and $13 \%$ among girls) were similar to those found in a community survey of 10 year olds in an inner London borough ( $25 \%$ among boys and $13 \%$ among girls), but considerably more than the corresponding rates for children on the Isle of Wight (14\% among boys and $7 \%$ among girls). ${ }^{6}$

There were wide discrepancies between a teacher's assessment of a child using the Rutter $B_{2}$ scale, and a parent's assessment of the same child using the Rutter $\dot{A}_{2}$ scale, and it was assumed that this was because mothers and teachers saw the children in different environments. Evidence from community studies ${ }^{78}$ and studies from psychiatric clinics," 10 however, suggest that the mothers' perceptions are influenced by their own affective disorders, and that these affect the way in which they assess the children's behaviour.

A pilot study in paediatric outpatient clinics in Leeds showed that mothers' mood disorders might be influencing their assessments of their children's behaviour. The first hypothesis of this study was, therefore, that maternal anxiety and depression would affect mothers' perceptions of their children's level of disturbance as measured by the Rutter $\mathrm{A}_{2}$ scale. Anxiety and depression in the mothers was measured by the hospital anxiety and depression scale. This scale has been validated locally, is easy to complete, and restricts the concept of depression almost entirely to 'anhedonia' (an inability to experience pleasure). The prevalence of maternal anxiety $(19 \%)$ was much greater than that of maternal depression (two mothers), presumably because of the more limited definition of depression implicit in this scale.

Maternal anxiety was significantly related to the likelihood of a child being considered to be disturbed by the mother and, using a stepwise logistic regression analysis, maternal anxiety proved the most important variable in predicting the mothers' assessments of their children's disturbances. This may be a genuine effect of anxiety on the mother's perception of the child, or it may be that disturbed children make their mothers anxious, or that a disturbed home background affects both mothers and children. While the latter hypotheses may be partly true, the fact that there was no increased likelihood of children with anxious mothers being seen as disturbed by their teachers strongly supports the hypothesis that maternal anxiety affects the mothers' perceptions of their children's disturbance.

There was a similar, but less important association between maternal depression and mothers' assessments of their children's disturbance. Other studies have shown that depression appreciably affects mothers' assessments of their children, ${ }^{89}$ and influences their use of medical facilities for their children. ${ }^{11}$

Table 2 shows that there are noticeable differences between mothers' and teachers' assessments of children's disturbance. The second most important variable affecting mothers' assessments was the size of the family, children from large families (four or more children) being significantly less likely to be disturbed according to their mothers. There was no evidence, however, that only children were particularly likely to be thought of as disturbed by their mothers. Conversely, teachers were more likely to regard children from large families as disturbed.

Unemployment of the head of the household significantly affected the teachers' assessments of the children, but not those of the mothers. This may be because antisocial and disruptive behaviour is more likely to manifest itself at school.

It seems that if a mother is asked to assess her child's disturbance using the Rutter $\mathrm{A}_{2}$ scale, that assessment will be subjective, and influenced by the mother's own mental state. Rutter $e^{a l^{2}}$ recommend that the teachers' and mothers' scales should be analysed together but, although the scales provide more information when used in this way, obtaining a teacher's assessment before an outpatient consultation is not usually practicable.

Severity of illness judged by a doctor had little effect on mothers' assessments of their children's 
disturbance using the Rutter $\mathrm{A}_{2}$ scale, although children with very serious illnesses were slightly more likely to be assessed as being disturbed by their mothers. Teachers, however, considered none of the very seriously ill children to be disturbed, possibly because teachers make allowances for disturbed behaviour if they know that a child is likely to die of his or her illness.

There was an insignificant trend for mothers of children with more serious illnesses to be more anxious. As there were only two definitely depressed mothers, no association could be found between maternal depression and severity of the child's illness. There was, therefore, some confirmation that mothers suffer more psychological disturbance as a result of the severity of their child's illness than do the children themselves.

This study has shown that the mothers' own moods have an important influence on their assessments of their children's behaviour. It may be unwise to assume that teachers are any more objective than mothers in their assessments of children, but it is clear that individual results from Rutter scales should be interpreted with caution. Self assessment scales for anxiety and depression were acceptable to mothers, and are useful to the clinician. Rapid scoring of the hospital anxiety and depression scale allows information about the mother's mental state to be made available during subsequent consultation, which should facilitate discussion about psychological factors related to a child's illness.

Measures of a child's psychological disturbance that depend on behaviour observed by adults have some value, but may be less informative than more direct assessments of the child's affective state. There are many problems to be overcome in finding a reliable measure of children's affective disorders, particularly within the constraints of an outpatient visit. ${ }^{12}$ In the absence of other suitable measures to make it easier to understand the whole child, paediatricians should continue to listen to the children themselves.

I thank Professor S R Meadow and Dr R P Snaith for their advice and encouragement with this study, Dr A D Clayden for statistical advice and performing the logistic regression analyses, and Drs Bailey, Brocklebank, Forsythe, Lewis, and Littlewood for permission to study patients under their care. This study was supported by a grant from the University of Leeds Research Fund.

\section{References}

1 Zigmond AS, Snaith RP. The hospital anxiety and depression scalc. Acta Psychiatr Scand 1983;67:361-70.

2 Rutter M, Tizard J. Whitmore K. Education, health and behaviour. London: Longman Green and Company, 1970.

${ }^{3}$ Birleson P. The validity of depressive disorder in childhood and the development of a self-rating scale: a research report. J Child Psychol Psychiatry 1981:22:73-88.

4 Rutter M. A children's behaviour questionnaire for completion by teachers. J Child Psychol Psychiatry 1967;8:1-11.

5 Fitzgerald, M. Behavioural deviance and maternal depressive symptoms in paediatric out-patients. Arch Dis Child 1985;60:560-2.

${ }^{6}$ Rutter M, Cox A, Tupling C, Berger M, Yule W. Attainment and adjustment in two geographical areas: 1 -The prevalence of psychiatric disorder. Br J Psychiatry 1975;126:493-509.

${ }^{7}$ Buck CW, Laughton KB. Family patterns of illness: the effect of psychoneurosis in the parent upon illness in the child. Acta Psychiatrica et Neurologica Scandinavica 1959;34:165-75.

* Fergusson DM, Horwood LJ, Gretton ME, Shannon FT. Family life events, maternal depression and maternal and teacher descriptions of child behaviour. Pediatrics 1985;75:30-5.

" Rickard KM, Forehand R, Wells KC, Griest DL, McMahon RJ. Factors in the referral of children for behavioural treatment: a comparison of mothers of clinic-referred deviant, clinic-referred non-deviant and non-clinic children. Behav Res Ther 1981:19:201-5

11" Schaughency EA. Lahey BB. Mothers and fathers perceptions of child deviance: roles of child behaviour, parental depression and marital satisfaction. J Consult Clin Psychol 1985;53:718-23.

11 Wolkind S. Mothers depression and their childrens' attendance at medical facilities. J Psychosom Res 1985:29:579-82.

12 Costello AJ. Assessment and diagnosis of affective disorders in children. J Child Psychol Psychiatry 1986;27:565-74.

Correspondence to Dr D B Cundall, Department of Paediatrics and Child Health. St James's University Hospital, Leeds LS9 7TF.

Received 13 March 1987 